QUADERNS DE FILOSOFIA VOL. V NÚM. 2 (20I 8): 29-48

eISSN: $234 \mathrm{I}-3042$ DOI: I 0.7203/QFIA.5.2.993 I

Sergio García-Rodríguez ${ }^{1}$

Universitat de les Illes Balears

\title{
Descartes y los frutos de la mecánica: la conquista de la buena vida terrenal
}

Descartes and the fruits of mechanics: the conquest of the earthly good life

Recibido: 2/3/2017. Aceptado: 25/7/2018

Resumen: El proyecto de Descartes profesa un notable interés encaminado al dominio de la naturaleza que, en última instancia, debe conducir al sujeto a vivir la mejor vida posible. A este propósito se dirigen los distintos frutos, resultado de la ciencia cartesiana: Medicina, Moral y Mecánica. El presente artículo analiza los frutos de la mecánica a fin de determinar su papel respecto a la consecución de una buena vida. Para ello se analizará el tipo de bien de que nos provee la mecánica, así como los distintos instrumentos que permiten su consecución.

Abstract: The Cartesian project professes a remarkable interest in the mastery of nature which, ultimately, leads the subject to live the best possible life. The various fruits of the philosophical tree which result from the Cartesian science-Medicine, Moral and Mechanics - are directed to this purpose. This paper analyzes the fruits of mechanics in order to determine its role in the achievement of a good life. For this purpose, it will be analyzed the kind of good which mechanics provides us and the various instruments necessary to achieve it.

Palabras clave: artefactos, artesanos, bienes terrenales, buena vida, comodidad, Descartes, frutos de la mecánica.

Keywords: artifacts, craftsman, Descartes, comfort, earthly goods, fruits of mechanics, good life.

\footnotetext{
${ }^{1}$ Contacto: grsergio91@hotmail.com
} 


\section{INTRODUCCIÓN}

T a Modernidad instaura la radical variación de la forma en que el sujeto _concibe su papel en el mundo, cuya consecuencia última radicará en la profunda transformación del ideal de vida hacia la revalorización de la existencia terrenal. En esa misma línea, el proyecto de Descartes, lejos de constituir una aspiración meramente teorética vinculada a la obtención de conocimiento como meta última, está dirigido hacia la búsqueda de la buena vida (AT IV, 228; VI, 22; IX-B, 13). ${ }^{2}$ El sujeto cartesiano representa el triunfo de las pretensiones renacentistas, cuyo fin no se circunscribe a la mera preservación de la vida sino a la conquista de la mejor vida terrenal posible, orientando, en consecuencia, su conocimiento teórico hacia fines prácticos bajo la máxima baconiana "el conocimiento es poder". Se trata, en definitiva, del triunfo del sujeto activo renacentista:

contra el ascetismo del Medioevo, contra la tendencia ascética del mundo antiguo; la vida monástica cristiana y la rigidez estoica son criticadas con idéntica vivacidad. Y, para esta lucha terrenal, se busca una recompensa terrenal; la individualidad, que quiere afirmarse por cualquier medio, desea extenderse en el tiempo y el espacio, desea dilatarse y romper los límites que la suerte del hombre ha establecido ${ }^{3}$

En este sentido, la ciencia representa para Descartes la praxis responsable de concedernos el conocimiento con el que "hacernos como dueños y poseedores de la Naturaleza" ${ }^{4}$ El símil del árbol de la filosofía expuesto en los Principios (AT IX-B, 15) no hace sino constatar este hecho: que el proyecto científico cartesiano se encamina hacia una traslación práctica, centrada en la búsqueda de resultados que se materialicen en nuestras vidas. Así, siguiendo esa imagen, se percibe cómo del tronco — que representa la física — brotan tres ramas: Moral, Medicina y Mecánica. Dichas disciplinas serán importantes por los frutos que nos permitan conquistar y que harán posible el gozar de una mejor vida, pues "como no se recogen los frutos del tronco ni de las raíces, sino

${ }^{2}$ Las referencias de la obra de Descartes expuestas en las notas al pie se acogerán a la edición clásica de Adam \& Tannery - a partir de ahora AT - (Euvres de Descartes (XII Vol.), París: Leopold Cerf, 1897-1913). Así, se indicará que la referencia pertenece a AT, junto con el correspondiente volumen y página. Las traducciones expuestas en el texto se realizarán, salvo que se indique una traducción propia, en base a la edición de Cirilo Flórez (Descartes, Madrid: Gredos, 2011), indicando su página correspondiente. Los Principios de la Filosofía y la Dióptrica se ceñirán a las traducciones de Guillermo Quintás (Principios de la filosofía, Madrid: Alianza Editorial, 1995), (Discurso del método, Dióptrica, Meteoros y Geometría, Madrid: Alfaguara, 1981).

${ }^{3}$ E. Garín, El hombre del Renacimiento, Madrid: Alianza, 1990, 67.

${ }^{4}$ Descartes, Discurso del método, 142 (AT VI, 62). 
sólo de las extremidades de las ramas, de igual modo la principal utilidad de la Filosofía depende de aquellas partes de la misma que sólo pueden desarrollarse en último lugar". ${ }^{5}$ En efecto, tales disciplinas dirigirán al sujeto hacia la obtención de distintos bienes sobre los que se funda precisamente la buena vida. De ese modo, mientras la Medicina centra su objetivo en la búsqueda de la salud (AT IV, 264; IV, 266; V, 327), la Moral se circunscribe a la consecución de los distintos contentos y el ejercicio de la virtud y la prudencia (AT IV, 264; IV, 274; IV, 275; V, 82). Ahora bien, ¿̇hacia dónde se encamina la Mecánica?

El presente artículo analiza los denominados "frutos de la mecánica" así como la función que estos desempeñan en la consecución de la mejor vida posible. Para ello, en primer lugar, se evidenciará el carácter eminentemente instrumental de la mecánica cartesiana a fin de mostrar cómo sus frutos son resultado de una intervención en el mundo por medio de artefactos que permite perfeccionar la calidad de la vida terrenal. Posteriormente, se determinará en qué sentido la mecánica puede contribuir a la obtención de una buena existencia terrenal. Para ello, se dilucidará qué estatuto poseen los bienes terrenales de la mecánica dentro de la moral cartesiana apelando a la noción de "comodidad" como el eje que permite definir sus aportaciones a la buena vida. Finalmente se analizarán distintos ejemplos de frutos de la mecánica expresados a lo largo del proyecto de Descartes con vistas a evidenciar casos concretos de cómo la mecánica permite una vida terrenal más cómoda.

I. LOS ORÍGENES DE LA MECÁNICA CARTESIANA: LA IMPRONTA DE LA MAGIA ARTIFICIAL REAL

La mecánica representa desde el principio una de las preocupaciones centrales del joven Descartes, quien dedica gran parte de la investigación científica de sus iuvenilia a cuestiones mecánicas como la hidráulica (AT X, 67-74). Si bien la mecánica había constituido tradicionalmente una disciplina resultante de la mera aplicación práctica de las matemáticas, ${ }^{6}$ Descartes cuestiona desde un primer momento dicho reduccionismo, redefiniendo el campo de la mecánica como perteneciente a la física (AT I, 421; II, 542; IX-B, 321), en tanto que "La Mecánica aborda los procesos físicos en términos de los movimientos sufridos por los cuerpos y la naturaleza de las fuerzas responsables de esos movimientos". ${ }^{7}$ El tratamiento mecánico de los fenómenos será realizado

${ }^{5}$ Descartes, Principios de la filosofía, 16 (AT IX-B, 15).

${ }^{6} \mathrm{Cf}$. D. Cappechi, The Problem of the Motion of Bodies. A Historical View of the Development of Classical Mechanics, Springer, 2014, 7.

${ }^{7}$ S. Gaukroger, Descartes'System of Natural Philosophy, Cambridge University Press, 2003, 93. 
por Descartes, en consecuencia, desde una novedosa perspectiva donde se conjugarán tanto física — pues, "la mecánica, considera las formas, tamaños y movimientos" —, como matemáticas, dando lugar a una fisica matematizada, tal y como el propio Beeckman subraya:

Los físico-matemáticos son poquísimos. Éste [Descartes] se ha educado con los jesuitas y otros hombres estudiosos, y dice, sin embargo, que nunca antes de mí ha encontrado a nadie que uniera en el estudio, como hago yo, la matemática con la física. E, igualmente, yo no había hablado a nadie de este modo de trabajar antes que a él ${ }^{9}$

Como ha señalado acertadamente Gaukroger, esta novedosa comprensión de la física cuestiona completamente la concepción aristotélica de la misma, "que explícitamente imposibilita plantear y resolver matemáticamente los problemas de la física” ${ }^{10} \mathrm{La}$ consecuencia más directa de la inclusión de la física en los problemas mecánicos se evidencia en el mejor control de los fenómenos naturales. Dada la reducción cartesiana de la materia a res extensa, cuyas propiedades —extensión, forma y movimiento — son plenamente cuantificables, la mecánica cartesiana, al combinar ambas disciplinas, facilitará un control calculístico pleno de los fenómenos sobre el que se establecerá su posterior dominio.

Es posible distinguir, dentro de los estudios cartesianos de mecánica, entre una vertiente teórica y una dimensión práctica (AT II, 232). La primera estaría representada por aquellos opúsculos orientados a solventar problemas técnicos como el Lapis in vacuo versus terrae centrum cadens (AT X, 75-8) o el De Solidorum elementis (AT X, 265-76), mientras que la faceta práctica de la mecánica cartesiana se circunscribiría a sus diversos frutos, esto es, a aquellos artefactos e ingenios diseñados por Descartes con capacidad para transformar efectivamente la vida de los hombres. La generación de efectos prácticos sometidos a control humano constituye, así, uno de los objetivos principales de la mecánica cartesiana cuyo origen ha tendido a ser situado en la denominada "tradición artesanal" de la Edad Media, donde artesanos como Roger Bacon o Villard de Honnecourt centraban su actividad en una práctica considerada "un 'saber hacer' más que un 'saber qué' [...] fundado en una experiencia acumulativa orientada especialmente hacia el logro de realizaciones prácticas". ${ }^{11}$ Siguiendo precisamente esa línea, autores como Burnett, interpretan dicho contexto

${ }^{8}$ Descartes, "Carta a Plempius del 3 de octubre de 1637” (AT I, 420). [Mi traducción]

${ }^{9}$ Descartes, "Diario de Beeckman" (AT X, 52).

${ }^{10}$ S. Gaukroger, "Descartes' Project for a Mathematical Physics" en S. Gaukroger (ed.), Descartes. Philosophy, Mathematics and Physics, The Harvest Press, 1980, 100.

${ }^{11}$ S. Turró, Descartes. Del hermetismo a la nueva ciencia, Anthropos, 1985, 103. 
como el responsable del interés práctico de la concepción artefactual cartesiana. Contrariamente, sin negar la posible relevancia de dicha tradición práctica, sostengo que la influencia más directa sobre la mecánica cartesiana aplicada se ubica en los intereses herméticos manifestados por Descartes en sus años de juventud, durante los cuales leyó "cuantos libros pudieron caer en [sus] manos referentes a las ciencias que se consideran como las más curiosas y raras" ${ }^{12} \mathrm{La}$ alusión a este tipo de ciencias, siguiendo la descripción del Dictionnaire Universel de Furetière (I690), refiere a aquellas disciplinas "que son conocidas por pocas personas y que poseen secretos particulares, como la química, una parte de la óptica que hace ver cosas extraordinarias mediante espejos y lentes" ${ }^{13}$ Por tanto, Descartes reconoce explícitamente que dedicó parte de su juventud entablar contacto con el hermetismo, cuyos artefactos mecánicos se encaminaban a la generación de efectos maravillosos. Así, sostengo que, mientras el influjo de la magia renacentista es evidente y explícito en sus iuvenilia, no hay constancia de que Descartes "trabajara con artesanos antes de sus días como óptico en París a mediados de 1620 ", ${ }^{14}$ por lo que sus aportaciones al campo de la mecánica muy probablemente sean fruto del interés cartesiano por el hermetismo.

La figura del mago renacentista encarna el espíritu de una nueva cosmovisión activa encaminada a la intervención en el mundo, pues su praxis hermética "expresa el aspecto práctico [...] [y] enseña que sobre la base de la identidad de sujeto y objeto, el sujeto no sólo comprende al objeto sino que además puede dominarlo". ${ }^{15}$ De ese modo, la explícita y reiterada mención de Descartes a magos renacentistas como Giambattista della Porta (AT III, 17; X, 348), Cornelio Agrippa (AT X, 165; X, 347) o Ramón Llull (AT VI, 17; X, 63-5) no deja duda alguna de la impronta del hermetismo sobre los intereses prácticos del cartesianismo. Aún más sugerente es la vinculación de Agrippa y Porta con la denominada "magia artificial real", una vertiente de la praxis hermética orientada hacia la construcción de artefactos que representará el intento más claro del sujeto activo renacentista de generar efectos asombrosos, sirviéndose para ello de la aplicación práctica de las matemáticas en el ejercicio de la mecánica a fin de establecer un dominio humano sobre la naturaleza. Esta tradición mágica instó a una constante revalorización de la función de las matemáticas aplicadas en la magia, como se evidencia en el Prefacio

${ }^{12}$ Descartes, Discurso del método, 103 (AT VI, 5).

${ }^{13}$ A. Furetière, Dictionnaire universel contenant genéralment tous les mots français tant vieux que modernes et les termes de toutes les sciences et des arts, Arnout et Reinier Leers, 1664, Vol. 1, 390.

${ }^{14}$ Gauvin, J. F., “Artisans, Machines, and Descartes’s Organon”, History of Science, 44 (2006): 196.

${ }^{15}$ E. CAssirer, Individuo y cosmos en la filosofía del Renacimiento, Buenos Aires: Emecé Ed., 1951, 214. 
matemático a los Elementos de Euclides de John Dee, cuyo propósito era "servir a la popularización de las matemáticas en lengua vernácula y mostrar cómo ellas podrían mejorar las artes y las invenciones”. ${ }^{16}$ En esa misma línea, Agrippa sostuvo la necesaria conexión entre la magia y las matemáticas hacia la consecución de resultados prácticos, pues:

Las ciencias matemáticas son tan necesarias para la Magia, y se relacionan tanto con ella, que quienes se dedican a ésta sin emplear aquéllas, no realizan nada de valor, pierden su tiempo, y jamás llegan al fin de sus designios [...] En la historia se observa, además, que las estatuas de Mercurio hablaban; y que la paloma de madera de Arquito volaba [...] Todas las maravillas derivadas de la Geometría y la Óptica son de esta índole [...] Así, cuando un mago que conoce la Filosofía natural y la Matemática y conoce las ciencias medias que de allí provienen, la Aritmética, la Música, la Geometría, la Óptica, la Astronomía y las ciencias que se ejercitan con pesos, medidas, proporciones, artículos y junturas; y que también conoce la Mecánica que de allí deriva, al estar por encima de los demás hombres a través del arte y del espíritu, realiza muchas cosas maravillosas que asombran muchísimo a los más sabios y esclarecidos ${ }^{17}$

El conocimiento por parte de Descartes de esta tradición mágica es evidente, dado que no solo alude a algunos de los artefactos presentes en dichos tratados de magia — como la paloma de Arquitas (AT X, 232-3) — , sino que también expone su reiterado interés en el análisis de diversas invenciones capaces de ocasionar efectos maravillosos. Ejemplos de ello son los distintos artefactos con espejos parabólicos mencionados en la Thaumantis Regia (AT $\mathrm{X}, 215-6)$ dirigidos, entre otras cosas, a "hacer aparecer en una habitación lenguas de fuego, carros de fuego y otras figuras en el aire; todo ello mediante determinados espejos que reúnan los rayos en aquellos puntos". ${ }^{18}$ Asimismo, Descartes dedica parte de su correspondencia a analizar el espejo ustorio gigante de Arquímedes diseñado para incendiar barcos a grandes distancias (AT I, 10910; II, 383; VI, 193-4), exponiendo la imposibilidad de su realización, dado que «los rayos del Sol no son todos paralelos, como solemos imaginar. Y si un ángel hubiera hecho un espejo para incendiar, si éste no tuviera más de seis toesas de diámetro [aproximadamente doce metros], no creo que tuviera fuerza suficiente como para hacer arder a una legua de distancia". ${ }^{19}$ Se evidencia, por

${ }^{16}$ G. E. SzónYI, John Dee’s Occultism: Magical Exaltation through Powerful Signs, State University of New York Press, 2005, 175.

${ }^{17}$ C. Agrippa, Filosofía oculta, Editorial Kier, 2005, Lib. II, cap.1, 21.

${ }^{18}$ Descartes, Thaumantis Regia (AT X, 216).

${ }^{19}$ Descartes, "Carta a Mersenne de enero de 1630" (AT I, 109-10). [Mi traducción] 
tanto, el influjo de la magia artificial real en el joven Descartes, cuya huella será responsable de la importancia otorgada a las matemáticas como instrumento para la materialización práctica de la mecánica. De esta forma, Descartes pone de manifiesto que "el resurgimiento general de la magia en el Renacimiento sirvió, en definitiva, para dar un notable impulso a la mecánica”. ${ }^{20}$ Se debe destacar, sin embargo, que la impronta del hermetismo en las matemáticas cartesianas no se redujo exclusivamente a su implementación práctica en la mecánica, pues se constata el influjo de otras tradiciones mágicas menos instrumentales como es el caso de la mágico-cabalística, cuyas similitudes con el álgebra establece Descartes en el Excerpta Mathematica (AT X, 297).

El progresivo abandono del hermetismo y su reemplazo por la nueva ciencia, evidente ya las Regulae, se traduce en una mayor relevancia de las matemáticas en el proyecto cartesiano tanto en su vertiente teórica, como en la práctica. Respecto a las novedosas funciones teóricas, si bien el joven Descartes "aún no advertía cuál era su verdadero uso, [...] pensando que sólo para las artes mecánicas servían", ${ }^{21}$ se considerará el modelo de certeza (AT I, 421; V, 176; VI, 7) que ejemplifican estas con vistas a la constitución de un conocimiento seguro. En lo concerniente al aspecto práctico, se preservarán las conexiones establecidas entre la magia artificial real y la mecánica cartesiana, garantizando la aplicación práctica de las matemáticas en el diseño de invenciones. Ahora bien, la construcción de artefactos ya no se encaminará a la obtención de efectos maravillosos (AT I, 21; IX, 309; X, 504) —destinados a ocasionar mera admiración en los hombres-, sino que las invenciones técnicas se dirigirán a la conquista de la naturaleza a fin de mejorar nuestra vida terrenal. Para ello, se procederá a una reevaluación del estatuto de lo artefactual cuya relevancia respecto a los frutos de la mecánica residirá en que "lo artificial no representa ya para Descartes un complemento de algo natural, sino la forma genuina en la que el sujeto puede influir en la naturaleza más allá del modelo expresado en lo natural", ${ }^{22}$ propiciando la libre intervención sobre la naturaleza y donde "la perspectiva del uso y de la utilidad es entonces el sustituto de la finalidad". ${ }^{23}$ Bajo ese propósito práctico, la ciencia cartesiana consumará las aspiraciones herméticas de dominio del mundo, convirtiendo el conocimiento de la física y las matemáticas en los instrumentos teóricos requeridos para la construcción de cualquier artefacto. Consecuentemente, Descartes no concebirá que la realización de invenciones pueda ya ser responsable del azar y no resultado de

${ }^{20}$ F. Yates, Giordano Bruno y la tradición hermética, Barcelona: Ariel, 1983, 176.

${ }^{21}$ Descartes, Discurso del método, 112 (AT VI, 7).

${ }^{22}$ S. García Rodríguez, "Dueños y poseedores de la naturaleza: la relación artificial-natural en la Dióptrica de Descartes", Contrastes. Revista internacional de filosofía vol. 21, 2 (2016): 87.

${ }^{23}$ P. Guenancia, Lire Descartes, París: Gallimard, 351. 
una ciencia - como sucede con aquellos que "sin conocer la naturaleza de los cielos, y aun sin observar siquiera con perfección los movimientos, esperan poder indicar sus efectos. Así la mayor parte de los que estudian la mecánica sin la física y fabrican al azar nuevos aparatos para producir movimientos". ${ }^{24}$ De esta forma, la ciencia cartesiana adquiere la tarea no solo de concebir y elaborar nuevos artefactos, sino incluso de perfeccionar aquellos resultado del simple azar (AT VI, 82-3) — como sucedía en la tradición artesanal-, pues estos repercuten tanto en la vida de los sujetos como en la propia investigación científica. $^{25}$

Descartes "no era un filósofo preocupado únicamente en establecer una certeza metafísica irrefutable. Él también era un matemático interesado en la práctica", ${ }^{26}$ y precisamente el influjo de la magia artificial real en el pensamiento cartesiano establece los pilares que otorgarán relevancia a la mecánica de Descartes como instrumento transformador de la realidad. Los frutos de la mecánica se realizan en forma de artefactos que, como se evidenciará, se encaminan a facilitar la consecución de una buena vida. En el próximo apartado se dirimirá el estatuto de los bienes de la mecánica en la conquista de la buena vida cartesiana.

\section{LA MECÁNICA Y LA BUENA VIDA CARTESIANA: LA COMODIDAD COMO BIEN TERRENAL}

El proyecto cartesiano se articula a partir de la noción de buena vida (AT IV, 228; VI, 22; IX-B, 13) como el eje que dota de sentido a su epistemología y su moral. Una epistemología como la de Descartes, encaminada primordialmente a la transformación del mundo, solo es posible en la medida en que dicha praxis está orientada hacia un fin. Es preciso, pues, que exista una meta última que guíe la intervención sobre el mundo, y es por ello que la teoría cartesiana de la buena vida establece la conquista de distintos bienes como el procedimiento correcto sobre el que se funda la consecución de los diversos contentos que conforman el buen vivir. La noción moderna de buena vida —en la que Descartes se enmarcará- es resultado de una nueva actitud frente al mundo surgida en el Renacimiento, que "restauró la confianza en la razón humana y $[\ldots]$ reconoció que la vida en este planeta poseía un valor independiente de cualquier temor o esperanza relacionados con una vida ultraterrena". ${ }^{27}$ En

\footnotetext{
${ }^{24}$ Descartes, Reglas para la dirección del espiritu, 16 (AT X, 380).

${ }^{25}$ Cf. G. Canguilhem, "Descartes et la technique", Trans/Form/Açao, vol. 5 (1982): 114-5.

${ }^{26}$ C. SASAKI, Descartes' Mathematical Thought, Springer, 2003, 421.

${ }^{27}$ J. Bury, La idea del progreso, Alianza, 1971, 37.
} 
consecuencia, la revalorización de la vida terrenal de raigambre renacentista, y consolidada definitivamente en la Modernidad, representa el requisito necesario para que la concepción moderna de bien vivir — a diferencia de la medieval ${ }^{28}$ - considere lo terrenal como parte de ella.

Descartes, como heredero de la cosmovisión renacentista, distingue entre dos tipos de bienes cuyas diferencias apelan al tipo de contento que nos proporcionan, así como a un distinto ámbito sobre el que se circunscriben. Por un lado, se hallan los denominados "bienes espirituales", como son la virtud o la prudencia (AT IV, 264), pertenecientes al ámbito de la res cogitans y responsables de otorgarnos el mayor contento del que nuestra alma puede gozar: la beatitud (AT IV, 264; IV, 274; IV, 275), que radica en "gozar de satisfacción y contento espirituales perfectos". ${ }^{29}$ Por otro lado, debemos considerar los "bienes terrenales", concernientes a la esfera corporal del sujeto (res extensa) y cuya consecución nos otorga un contento corporal, denominado por Descartes "agradable sensación sensitiva" (chatouillement) (AT IV, 312; XI, 144; XI, 158; XI, 430), que es, en comparación, más volátil e imperfecto que la beatitud. Siguiendo la descripción de Furetière, esta agradable sensación sensitiva se trata de un "sentimiento que da placer al cuerpo"..$^{30}$ Por tanto, dicho contento esta intrínsecamente vinculado a la dimensión corporal del hombre y no tiene contacto con su dimensión espiritual, por lo que se explica únicamente en términos fisiológicos apelando a los movimientos de las fibras del cuerpo (AT XI, 399). La interpretación canónica de la moral cartesiana ha tendido a privilegiar la obtención de los bienes espirituales y de la beatitud como el principal objetivo de la moral cartesiana. Bajo esta perspectiva, la beatitud representa el fundamento único sobre el que se asienta la buena vida, pues el contento que ella nos brinda es duradero y dota a nuestra alma de una tranquilidad que no puede ser perturbada por nuestras pasiones. Esta lectura, a su vez, ha ido acompañada de una percepción denostada de los bienes terrenales, donde éstos, en la medida en que son volátiles y azarosos, no deben ser perseguidos a fin de maximizar la búsqueda de los bienes espirituales.

${ }^{28}$ Hallamos a lo largo de la Edad Media un desdén hacia la vida terrenal y sus placeres, junto a una preferencia clara por la vida contemplativa con la esperanza del sujeto situada en la vida ultraterrenal. De hecho, a lo largo del siglo XII esta animadversión hacia lo terrenal se recrudece, surgiendo toda una "tradición de escritos sobre el desprecio al mundo [...] [en] obras como el Apologeticum de comptu saeculi de Pedro Damián, la Exhortatio ad contemptum temporalium et desiderium aeternorum de San Anselmo de Canterbury, [o] las Meditationes piisimae de cognitione humanae conditionis de Bernardo de Claraval" (M. J. VEGA, "La exaltación de los humildes. El De Miseria humanae conditionis de Inocencio III", Propaladia, 5 (2011): 2-3).

${ }^{29}$ Descartes, "Carta a Isabel del 4 de agosto de 1645", 586 (AT IV, 264).

${ }^{30}$ A. FuRETIÈRE, Dictionnaire universel contenant genéralment tous les mots français tant vieux que modernes et les termes de toutes les sciences et des arts, Arnout et Reinier Leers, 1664, Vol. 1, 388. 
De hecho, algunos fragmentos apuntalan esta interpretación, pues el propio Descartes reconoce que "como son siempre inferiores las [satisfacciones] del cuerpo, podemos decir en términos generales que sin ellas es posible ser feliz". ${ }^{31}$ Así, bajo esta lectura, el bien vivir se logra únicamente mediante la conquista de la beatitud, por lo que los bienes terrenales quedarán despojados de cualquier relevancia en esa buena vida.

Contra esta interpretación, sostengo que, si bien la "perfección ontológica del espíritu justifica la superioridad de los bienes del [espirituales] sobre aquellos del cuerpo [terrenales]", ${ }^{32}$ ello no implica el rechazo de los bienes terrenales, dado que la consecución de la mejor vida posible constituirá, desde la óptica cartesiana, una conjunción de ambos tipos de bienes, pues "el soberano bien de todos los hombres juntos es un conjunto o reunión de todos los bienes, tanto del alma como del cuerpo y de la fortuna". ${ }^{33}$ Esta interpretación de la moral cartesiana difiere de la lectura canónica, ${ }^{34}$ en tanto que, al centrarse exclusivamente en la consecución de la beatitud y en el rechazo de los bienes terrenales, incurre en una grave contradicción. Ciertamente, si el proyecto científico cartesiano tiene el propósito de constituir "una ciencia útil para la vida", ${ }^{35}$ sirviéndose para ello de la intervención en el mundo a fin de conquistar determinados bienes terrenales, ello es inconsistente con una perspectiva moral que rechace la relevancia de los propios bienes terrenales. La solución de esta inconsistencia radica en que, aun cuando sea posible disfrutar de una buena vida apelando exclusivamente a la beatitud (AT IV, 264), la mejor vida posible precisará, además, de los bienes terrenales —a los que Descartes consagra su proyecto científico, cuyo resultado último se encamina hacia su conquista mediante el dominio de la naturaleza-. Adviértase el énfasis realizado en la distinción entre disfrutar de una buena vida y gozar de la mejor vida posible, donde son los bienes terrenales quienes establecen la diferencia entre ambas nociones, otorgando sentido a la conquista cartesiana de la naturaleza. Ciertamente, si la más perfecta existencia del sujeto precisara únicamente de los bienes espirituales, ello implicaría una contradicción respecto la consecución de los bienes terrenales a la que se encamina el proyecto científico cartesiano, pues éstos no serían requeridos para lograr vivir bien. De ahí que Descartes abogue por una conjunción de ambas, donde "La virtud y la sabiduría son suficientes para un contento completo $[\ldots]$ pero donde los bienes externos son requeridos

${ }^{31}$ Descartes, "Carta a Isabel del primero de septiembre de 1645”, 598 (AT IV, 287).

${ }^{32}$ G. Rodis-Lewis, La Morale de Descartes, París: PUF, 1970, 44.

${ }^{33}$ Descartes, "Carta a la Reina Cristina del 20 de noviembre de 1647", 471-2 (AT V, 82).

${ }^{34}$ O. Hamelin, Le Système de Descartes, París: Félix Alcan, 1921, 218-9 ; G. Rodis-Lewis, La Morale de Descartes, París: PUF, 1970, 43-9.

${ }^{35}$ G. Canguilhem, "Descartes et la technique”, Trans/Form/Açao, vol. 5 (1982): 111. 
para un contento aún más perfecto" ${ }^{36}$ En consecuencia, las apodadas almas elevadas (AT I, 632; IV, 203-4; XI, 453-4) — sujetos que encarnan la correcta búsqueda de la buena vida cartesiana - efectuarán una apropiada reunión de las dos nociones de bien, en tanto que el "deleite del alma en que consiste la beatitud no es inseparable del regocijo y el bienestar del cuerpo". ${ }^{37}$

Los frutos de la mecánica se circunscribirán al ámbito de acción de los bienes terrenales, otorgando al sujeto un contento vinculado exclusivamente a su dimensión corporal. Ahora bien, mientras la Medicina será encargada de otorgarnos el bien de la salud (AT IV, 220; V, 327; VI, 62), "el mayor de todos los bienes relativos a nuestro cuerpo", ${ }^{38}$ Descartes no explicita cuáles son los bienes resultado de la aplicación práctica de la Mecánica. Esta disciplina, en tanto que perteneciente a las ramas de la física es, junto a la Medicina y la Moral, responsable de proveernos de aquellos bienes con los que lograr la mejor vida, pues "no se recogen los frutos del tronco ni de las raíces, sino sólo de las extremidades de las ramas", ${ }^{39}$ por lo que es preciso dilucidar el tipo de bienes de los que nos pertrecha la mecánica. La tesis que se defenderá en el presente artículo sostiene que el bien terrenal resultado de la mecánica es la "comodidad" (commodité) (AT VI, 31; VI, 62; VI, 163; X, 361).

En efecto, Descartes manifiesta en diversas ocasiones la importancia de disfrutar de una vida cómoda. Así, recuerda a su amigo Balzac los beneficios de vivir en la ciudad en comparación a la vida campestre, la cual "carece de una infinidad de comodidades [commoditez] que solo se encuentran en las ciudades" ${ }^{\prime 4}$ — un consejo que guiará el modus vivendi del propio Descartes (AT VI, 31). Por vida cómoda se debe entender aquella resultado de "facilitar las artes todas y disminuir el trabajo de los hombres" ${ }^{41}$ sirviéndose para ello de "una infinidad de artificios que nos permitirían gozar sin ningún trabajo de todos los frutos de la tierra y de todas las comodidades que hay en ella" ${ }^{42}$ Como se ha sostenido anteriormente, la aplicación práctica de la mecánica tiene como fruto el diseño y construcción de diversos artefactos que constituirán la herramienta cartesiana con que mejorar la vida del sujeto. La ciencia de Descartes procurará el bagaje teórico que permita lograr dichas invenciones, pues "cuando cultivamos las ciencias por la utilidad que reportan para la comodidad de la vida [vitae commoda] [...] podemos esperar de las

\footnotetext{
36 J. Marshall, Descartes' Moral Theory, Cornell University Press, 1998, 61.

${ }^{37}$ Descartes, "Carta a Isabel del 6 de octubre de 1645", 608 (AT IV, 409).

${ }^{38}$ Descartes, "Carta a Chanut del 31 de marzo de 1649", (AT V, 327). [Mi traducción]

${ }^{39}$ Descartes, Principios de la filosofía, 16 (AT IX-B, 15).

${ }^{40}$ Descartes, "Carta a Balzac del 5 de mayo de 1631", (AT I, 203). [Mi traducción]

${ }^{41}$ Descartes, Discurso del método, 104 (AT VI, 6).

${ }^{42}$ Descartes, Discurso del método, 142 (AT VI, 62).
} 
ciencias estos legítimos frutos". ${ }^{43}$ Esta interpretación se opone, por tanto, a la caracterización de Arenas, donde se reduce la comodidad que las tecnologías mecánicas representan al mero facilitar las tareas productivas, ${ }^{44}$ pues esta impide una comprensión más amplia de la noción de comodidad que se precisa a fin de abordar la totalidad de los artefactos cartesianos — como se evidenciará en el próximo apartado - . En consecuencia, la vida cómoda no es sino resultado del dominio de la naturaleza ejercido por las ciencias por medio de los artefactos, haciendo posible una transformación de las condiciones materiales del ser humano — tal y como se destaca en el Discurso (AT VI, 62)_. Asimismo, la asunción de la comodidad como fin práctico propio de los artificios pone de manifiesto el reemplazo de los efectos maravillosos por nuevas finalidades encaminadas a hacer más confortable la existencia terrenal de los sujetos.

\section{Hacia una vida terrenal cómoda: los artefactos propuestos POR DESCARTES}

Una vez expuesta la función que desempeñan los frutos de la mecánica dentro del proyecto moral cartesiano - dotar al sujeto de una existencia material más perfecta que se conjugue con la búsqueda de la beatitud-, es preciso determinar en qué modo las máquinas contribuyen a ello. El presente apartado expone una categorización de los tipos de "comodidades" que los distintos artefactos pueden brindarnos así como ejemplos de aquellas máquinas diseñadas por Descartes que contribuyen a tales fines.

Descartes es responsable del diseño de innumerables artefactos cuyo objetivo es facilitar al sujeto una vida cómoda. Este propósito guía las investigaciones científicas cartesianas desde muy temprano, como demuestra la amplia correspondencia colaborativa con artesanos como Ferrier (AT I, 32-8; I, 53-69; II, 373-6) o con ingenieros como Villebressieu ${ }^{45}$ (AT I, $212-$ 7). De hecho, ese contacto no debe sorprendernos considerando que la tarea cartesiana respecto a los artefactos se ciñe a proporcionar el bagaje teórico que dirige la construcción de las invenciones, no obstante, "en relación a las cuestiones prácticas, le dej[a] eso a los artesanos". ${ }^{46}$ En efecto, la realización

${ }^{43}$ Descartes, Reglas para la dirección del espiritu, 4 (AT X, 361).

${ }^{44}$ Cf. L. Arenas, "Descartes y la racionalización técnica de lo real", Thémata. Revista de Filosofía, 26 (2001): 38-9.

${ }^{45}$ De hecho, Baillet enumera varios inventos de Villebressieu que fueron construidos siguiendo las sugerencias de Descartes, como "La grúa para atravesar un lugar que tenga un largo y profundo foso [...] [o] el barco para atravesar ríos formado por cuatro tablones que se pliegan y se llevan bajo el brazo" (A. Baillet, La Vie de Monsieur Descartes, vol. I, París, 1691, 258).

${ }^{46}$ Descartes, "Carta a Mersenne del 15 de noviembre de 1638", (AT II, 447). [Mi traducción] 
material es, a ojos de Descartes, una cuestión que concierne exclusivamente a los artesanos ${ }^{47}$ responsables de solventar "la brecha entre teoría y práctica". ${ }^{48}$ Así, la propuesta cartesiana procura las herramientas teóricas que permiten la realización práctica de las invenciones, tal y como sucede en la Dióptrica que no es sino "un manual de instrucciones para los artesanos o los técnicos". ${ }^{49}$ Los artefactos de Descartes pueden ser divididos entre: aquellos que nos "proporcionan una gran ventaja para nuestro conocimiento de la naturaleza" 50 al mejorar la investigación científica — como el telescopio (AT II, 513; VI, 201-6) o el microscopio (AT I, 330-1; VI, 206-10)—, y aquellos encaminados a la obtención de comodidades para la vida del sujeto. Entre estos últimos podemos considerar artefactos que satisfacen dicho cometido en dos posibles formas. En primer lugar, hallamos los artificios que facilitan las labores (AT VI, 6; VI, 62) que el ser humano necesita desempeñar a fin de garantizar su subsistencia. La segunda categoría, se circunscribe a aquellos artificios que permiten la supresión de incomodidades, mejorando la forma en que los sujetos se conducen en el mundo.

En relación a las invenciones cartesianas destinadas a facilitar las tareas materiales de los hombres, éstas podrían considerase bajo el rubro empleado por Arenas de "tecnologías productivas", cuyo objetivo es liberar "al trabajador de parte del esfuerzo físico que supone la existencia material de las sociedades". ${ }^{51}$ En este sentido, el mejor ejemplo lo hallamos en el Tratado de la mecánica (AT I, 435-47) donde Descartes presentará una serie de artefactos, resultado de la aplicación práctica de la mecánica, cuyo objetivo principal es hacer la vida más cómoda al sujeto —en el sentido de "facilitar las artes todas y disminuir el trabajo de los hombres" 52 - al permitirle tanto elevar, como transportar cargas pesadas utilizando una fuerza menor a la usual. Entre los artificios propuestos hallamos, por ejemplo, la polea (poulie), la rueda dentada (roue ou tour) o el plano inclinado (plan incliné). En el caso de la polea, Descartes sostiene que a través de una combinación de varias de ellas es posible elevar cómodamente

${ }^{47}$ No deja de ser interesante la concepción negativa que Descartes explicita respecto al papel de los artesanos como culpables del fracaso en la realización práctica de numerosos artefactos. Para un interesante análisis de la cuestión véase: J. F. Gauvin, "Artisans, Machines, and Descartes's Organon", History of Science, 44 (2006): 194-6.

${ }^{48}$ G. BurnetT, "Descartes and the Hyperbolic Quest: Lens Making Machines and their Significance in the Seventeenth Century", Transactions of the American Philosophical Society (2005): 124.

${ }^{49}$ N. M. Ribe, "Cartesian Optics and the Mastery of Nature", Isis, 88-1 (1997): 48.

${ }^{50}$ Descartes, Dióptrica, 175 (AT VI, 226).

${ }^{51}$ L. Arenas, "Descartes y la racionalización técnica de lo real", Thémata. Revista de Filosofía, 26 (2001): 38.

${ }^{52}$ Descartes, Discurso del método, 104 (AT VI, 6). 
un peso, pues "aumentando el número de poleas, podemos elevar las mayores cargas con las más pequeñas fuerzas", ${ }^{53}$ de forma que, "No se necesitará más fuerza para levantar un peso de doscientas libras que para levantar un peso de cincuenta libras sin poleas". ${ }^{54}$ La explicación de Descartes se funda en que las distintas poleas van duplicando la fuerza, así "la tercera polea triplica la fuerza de la primera, y la cuarta la cuadruplica, y la quinta la quintuplica, y así al infinito, entendiendo que esas poleas dependen la una de la otra" ${ }^{55}$ Por tanto, el ingenio de la combinación de poleas facilita el trabajo de aquellos que deban elevar pesos, con lo que "perdemos tanta fuerza como tiempo ganamos". ${ }^{56} \mathrm{El}$ plano inclinado constituirá, por otro lado, una invención destinada a transportar más cómodamente grandes pesos, de forma que "Si solo tenemos fuerza suficiente para mover una carga de 100 libras y deseamos trasladar el cuerpo $\mathrm{F}$ que pesa 200 libras [...] lo único que debemos hacer es empujarlo [...] [a través de un plano inclinado]". ${ }^{57}$

Cabe apuntar que las investigaciones mecánicas de Descartes explorarán, más allá de este opúsculo, otro tipo de invenciones vinculadas a facilitar el trabajo de los hombres como, por ejemplo, el tornillo de Arquímedes (AT II, 632; III, 232) — considerado por Descartes el mejor instrumento para extraer agua-:

La forma que yo considero la mejor para elevar el agua muy alto es mediante una vara donde en un extremo se coloca un receptáculo para el agua, que de nuevo elevará el agua, por medio de una bomba u otro artefacto, a un receptáculo [...] yo encuentro el tornillo de Arquímedes más adecuado que cualquier otro instrumento: porque con la bomba se pierde demasiada fuerza ${ }^{58}$

Los artefactos encaminados a la corrección de incomodidades corporales conformarán la otra vertiente a la que se dirijan los frutos de la mecánica. En efecto, Descartes menciona la existencia de determinadas afecciones que, aun cuando no conllevan la muerte del individuo, suponen un descenso en la calidad de vida de los sujetos al dificultar la forma en la que se mueven en el mundo. ${ }^{59}$ El mejor ejemplo de ello lo constituyen las denominadas

${ }^{53}$ Descartes, Tratado de mecánica, (AT I, 438). [Mi traducción]

${ }^{54}$ Descartes, "Carta a Mersenne del 13 de julio de 1638", (AT II, 231). [Mi traducción]

55 Descartes, "Carta a Mersenne del 30 de septiembre de 1640", (AT III, 186). [Mi traducción]

${ }^{56}$ Descartes, "Carta a Mersenne del 29 de enero de 1640", (AT III, 13). [Mi traducción]

${ }^{57}$ Descartes, Tratado de mecánica, (AT I, 439). [Mi traducción]

${ }^{58}$ Descartes, "Carta a Mersenne del 25 de diciembre de 1639”, (AT II, 631-2). [Mi traducción]

59 Cf. S. García Rodríguez, "Función natural y salud: la teleología médica cartesiana", Estudios filosóficos, vol. LXVI (2017): 329-31. 
"incomodidades de la vejez" (AT I, 439; II, 480; VI, 62), donde es posible ubicar la progresiva pérdida de visión de cerca (presbicia), resultado de que "los ojos [que] se forman al principio un poco más largos y estrechos de lo que debieran ser [...], posteriormente, a medida que se envejece, pasan a ser más planos y anchos". ${ }^{60} \mathrm{Si}$ bien los remedios a dichos problemas de salud parece que debieran pertenecer al ámbito de la Medicina, Descartes afirma muy claramente en la Dióptrica que su remedio, al apelar a artefactos, se circunscribe al dominio de la mecánica, pues "[...] la Medicina, [trata de] remediar los defectos de la vista mediante la corrección de los órganos naturales. [Mientras que] [...] la Dióptrica, $[\ldots]$ intenta remediar los mismos defectos mediante la aplicación de algunos órganos artificiales" ${ }^{61}$ De esta forma, la invención propuesta por Descartes a fin de abordar los problemas de visión serán las gafas, pudiendo distinguir entre aquellas destinadas a problemas para la visión de lejos (lunnetes à puces) (AT I, 62; II, 455; III, 177) y aquellas dirigidas a mejorar la visión de cerca (lunnetes d'approche) (AT II, 455; III, 579). Es cierto que los anteojos no representan una genuina invención cartesiana - ya Vitelio o Roger Bacon habían realizado distintas propuestas de anteojos-, no obstante, su intención en la Dióptrica no era sino perfeccionar el diseño resultado del mero azar, definiendo la forma que debían tener las lentes en base a todos los factores fisiológicos y físicos explorados por la ciencia cartesiana. En este sentido, la propuesta artefactual cartesiana conforma una trascendental ruptura respecto a la tradición artesanal:

Los escritos técnicos medievales dan amplias y detalladas instrucciones sobre el modo de "elaborar", se presentan como un conjunto de reglas, de recetas, de preceptos; [ahora bien] la "teoría", entendida como intento de obtener los preceptos a partir de principios generales y de fundamentarlos en un conjunto de hechos verificables, se halla ausente en absoluto de aquellos "tratados" del Medievo $^{62}$

Ciertamente, el descubrimiento de la ley de refracción (AT VI, 93-105) o las sólidas descripciones de los mecanismos fisiológicos del ojo (AT VI, 1068; XI, 151-7) constituían conocimientos científicos que situaban a Descartes en una mejor posición teórica para determinar la correcta forma que las lentes debían poseer a fin de corregir de forma efectiva los defectos de la visión. Así, las lentes perfeccionadas, resultado de la ciencia cartesiana, permitirían suprimir los problemas de visión, conduciendo a una vida más cómoda a sus usuarios,

${ }^{60}$ Descartes, Dióptrica, 112 (AT VI, 150).

${ }^{61}$ Descartes, Dióptrica, 126 (AT VI, 164-5).

${ }^{62}$ P. Rossi, Los filósofos y las máquinas, Labor, 1970, 41. 
pues "Toda la conducta de nuestra vida depende de nuestros sentidos", ${ }^{63}$ de forma que resolver las incomodidades no es sino hacer más cómoda la forma de moverse en el mundo.

Siguiendo el símil del árbol de la filosofía expuesto en la Carta-prefacio de los Principios, las máquinas e ingenios de la mecánica no brotan sino del tronco del árbol que representa la Física. Por tanto, los frutos de la mecánica son producto de un conocimiento científico que ofrece el bagaje teórico sobre el que desarrollar del modo más perfecto el diseño y construcción de los distintos artefactos. Será esta relación entre teoría y práctica la que permitirá la elaboración de máquinas con que alcanzar adecuadamente el bien terrenal que representa la comodidad en sus dos manifestaciones posibles.

\section{Conclusión}

El proyecto cartesiano, heredero de la cosmovisión renacentista del sujeto activo, se encamina hacia una transformación de la realidad donde la búsqueda de una mejor vida terrenal representa la meta última que permite dotar de sentido y dirigir la propia intervención sobre el mundo. En este sentido, los frutos de la mecánica constituyen uno de los productos de la praxis transformadora mediante los que someter la naturaleza a los designios humanos a fin de disfrutar de una mejor existencia terrenal. A través de los distintos artefactos anteriormente expuestos como el tornillo de Arquímedes o las distintas lentes que corrigen defectos de la visión, el ser humano puede gozar de una existencia liberada de incomodidades corporales que redunde en una mayor calidad de vida. Por tanto, los artificios mecánicos cartesianos constituirán aquellos frutos que nos permitirán conquistar un determinado tipo de bien que contribuye a disfrutar de una mejor vida terrenal: la comodidad. Los distintos ingenios expuestos dirigen al sujeto hacia una vida más cómoda, bien facilitando el desempeño de las tareas productivas de los hombres con menor esfuerzo, bien remediando a través de artefactos las incomodidades corporales. Asimismo, tal y como se ha expuesto, esta comprensión de los frutos de la mecánica se articula plenamente en el proyecto moral cartesiano. La búsqueda de la buena vida del sujeto no se reduce a la mera consecución de la beatitud sino que, desde la óptica cartesiana, es preciso conjugar ésta junto a la conquista de los bienes terrenales, pues éstos permitirán al sujeto disfrutar de la mejor existencia terrenal (AT V, 82). Es necesario subrayar que la interpretación de la moral cartesiana entendida en términos exclusivos de la beatitud y vinculada a un profundo

${ }^{63}$ Descartes, Dióptrica, 59 (AT VI, 81). 
rechazo de todos los bienes terrenales recae en una grave contradicción en la medida que su proyecto científico tiene como meta principal la consecución de bienes que permitan mejorar las condiciones materiales de los hombres. Precisamente por ello, el propio Descartes afirmará que el bien vivir concilia los bienes materiales y espirituales, de forma que "el soberano bien de todos los hombres juntos es un conjunto o reunión de todos los bienes, tanto del alma como del cuerpo y de la fortuna". ${ }^{64}$ Se rompe, así, la imagen de la moral cartesiana fundamentada en "un ejercicio de distanciamiento de lo material y de todo aquello cuyo intento de conquista haría palmariamente visible la escasa potencia humana", ${ }^{65}$ construida exclusivamente sobre los bienes intelectuales del cogito. El hombre cartesiano conforma una unión substancial de mente y cuerpo, de modo que se debe atender a los bienes relativos a cada una de las substancias que componen dicha unión a fin de lograr la mejor vida posible. Por tanto, los frutos de la mecánica serán aquellos relativos a la dimensión corporal del hombre que proveerán al ser humano del bien de la comodidad materializado en las distintas máquinas y artefactos.

A fin de poder desarrollar plenamente el carácter transformador de la acción humana, Descartes establece una sólida relación entre ciencia y técnica, donde la primera proveerá de los conocimientos teóricos que harán posible la materialización práctica de los distintos artefactos. En este sentido es preciso recordar que la Modernidad transforma las relaciones entre artesanos y científicos, de forma que "que la colaboración entre saber técnico y saber científico que viene a hacerse habitual a comienzos de la edad moderna ha de ser considerado como uno de los aspectos centrales y fundamentales de la nueva cultura". ${ }^{66}$ Así, en la línea propia de la Modernidad, el repudio de la tradición artesanal que efectúa Descartes se fundamentará en la imposibilidad de construir máquinas realmente útiles y perfectas si se carece de una explicación científica que sustente su diseño. A juicio de Descartes, será preciso establecer una conexión entre teoría y praxis donde la ciencia provea del bagaje teórico y se encargue del correcto diseño de los artefactos con vistas a disponer de las máquinas más perfectas — tal y como se evidencia en la Escuela de Artesanos proyectada por Cartesio (AT XI, 659-60)—. Así pues, la concepción cartesiana de la tecnología debe ser considerada como partícipe de lo que los estudios de CTS han denominado "modelo unidireccional del progreso científico", donde se establece un nexo definido en el que la tecnología representa siempre una materialización práctica del conocimiento científico. Consecuentemente,

${ }^{64}$ Descartes, "Carta a la Reina Cristina del 20 de noviembre de 1647”, 471-2 (AT V, 82).

${ }^{65}$ R. LÁzAro, "Pasión y virtud en la moral cartesiana", Pensamiento. Revista de investigación e información filosófica, 65, 244 (2009): 334.

${ }^{66}$ P. Rossi, Los filósofos y las máquinas, Labor, 1970, 43. 
se sostiene que la tecnología siempre es un producto resultante de la teoría científica previamente desarrollada, de modo que esta vinculación entre teoría y praxis conlleva un progreso material inexorable en la medida en que es el conocimiento científico aquello que garantiza el correcto diseño y elaboración de los distintos artefactos mediante los que mejoran las condiciones de existencia material. Este esquema operatorio es el que se percibe en los frutos de la mecánica, donde Descartes explicita siempre la importancia de disponer de una comprensión física y matemática a fin de poder desarrollar los distintos artefactos. ${ }^{67}$ Por tanto, los frutos de la mecánica y el progreso que ellos entrañan mediante el bien de la comodidad serán posibles tan solo a luz de una ciencia previa que permita guiar su diseño y construcción.

En definitiva, el proyecto cartesiano consuma la revalorización de la vida terrenal y propone como meta última la conquista de una buena vida donde los distintos bienes terrenales de la mecánica permitirán al ser humano disfrutar de un verdadero progreso material liberado de incomodidades.

${ }^{67}$ Un ejemplo claro de cómo Descartes critica duramente aquellas invenciones que se elaboran al margen de una explicación científica lo encontramos en el caso del diseño de las primeras lentes parabólicas por Santiago Metio (AT VI, 80). 


\section{BIBLIOGRAFÍA}

Agrippa, C. 2005 , Filosofía oculta. Tratado de magia y ocultismo, Buenos Aires: Editorial Kier.

Arenas, L. 200I, "Descartes y la racionalización técnica de lo real", Thémata. Revista de Filosofía, 26: 27-40.

Baillet, A. i691, La Vie de Monsieur Descartes, vol. I, París.

Burnett, G. 2005, "Descartes and the Hyperbolic Quest: Lens Making Machines and their Significance in the Seventeenth Century", Transactions of the American Philosophical Society: 1-155.

Bury, J. I97 I, La idea del progreso, Madrid: Alianza.

Canguilhem, G. 1982, "Descartes et la technique", Trans/Form/Açao, 5: 111-22.

Cappechi, D. 2014, The Problem of the Motion of Bodies. A Historical View of the Development of Classical Mechanics, Nueva York: Springer.

Cassirer, E. I95 I, Individuo y cosmos en la filosofía del Renacimiento, Buenos Aires: Emecé Ed.

Descartes, R. i 897-i9i3, Euvres de Descartes (XII Vol.), Adam, C. y Tannery, P. (ed.), París: Leopold Cerf.

Descartes, R. i981, Discurso del método, Dióptrica, Meteoros y Geometría, Quintás, G. (trad.), Madrid: Alfaguara.

Descartes, R. I995, Principios de la filosofía, Quintás, G. (trad.), Madrid: Alianza Editorial.

Descartes, R. 20 i i, Descartes, Flórez, C. (ed.), Madrid: Gredos.

Furetière, A. I664, Dictionnaire universel contenant genéralment tous les mots français tant vieux que modernes et les termes de toutes les sciences et des arts, La Haya : Arnout et Reinier Leers.

García Rodríguez, S. 20i6, "Dueños y poseedores de la naturaleza: la relación artificial-natural en la Dióptrica de Descartes", Contrastes. Revista internacional de filosofía, vol. 21, 2: 75-90.

García Rodríguez, S. 2017, "Función natural y salud: la teleología médica cartesiana", Estudios filosóficos, LXVI: 313-34.

Garín, E. I990, El hombre del Renacimiento, Madrid: Alianza.

Gaukroger, S. i980, "Descartes' Project for a Mathematical Physics", en S. Gaukroger (ed.), Descartes. Philosophy, Mathematics and Physics, Sussex: The Harvest Press, 97-140.

Gaukroger, S. 2003, Descartes' System of Natural Philosophy, Cambridge: Cambridge University Press.

Gauvin, J. F. 2006, “Artisans, Machines, and Descartes's Organon”, History of Science, 44: 187-216. 
Guenancia, P. 2000, Lire Descartes, París: Gallimard.

Hamelin, O. i92 I, Le Système de Descartes, París: Félix Alcan.

LÁzaro, R. 2009, "Pasión y virtud en la moral cartesiana", Pensamiento. Revista de investigación e información filosófica, 65, 244: 313-38.

Marshall, J. 1998, Descartes's Moral Theory, London: Cornell University Press.

Ribe, N. M. 1997, "Cartesian Optics and the Mastery of Nature", Isis, 88-1: 4261.

Rodis-Lewis, G. I970, La Morale de Descartes, París: PUF.

Rossi, P. 1970, Los filósofos y las máquinas (1400-1700), Barcelona: Labor.

SASAKI, C. 2003, Descartes' Mathematical Thought, Londres: Springer.

SzónyI, G. E. 2005, John Dee's Occultism: Magical Exaltation through Powerful Signs, Nueva York: State University of New York Press.

Turró, Salvi 1985, Descartes. Del hermetismo a la nueva ciencia, Barcelona: Anthropos.

Vega, M. J. 20I I, "La exaltación de los humildes. El De Miseria humanae conditionis de Inocencio III", Propaladia, 5.

Yates, F. 1983, Giordano Bruno y la tradición hermética, Barcelona: Ariel. 